\title{
The European Framework for Regulating Telecommunications: A 25-year Appraisal
}

\author{
Martin Cave ${ }^{1} \cdot$ Christos Genakos $^{2,3,4,5}$ (D) $\cdot$ Tommaso Valletti ${ }^{5,6,7,8}$
}

Published online: 26 February 2019

(c) The Author(s) 2019

\begin{abstract}
The European telecommunications sector has been radically transformed in the past 25 years: from a group of state monopolies to a set of increasingly competitive markets. In this paper we summarize how this process has unfolded-for both fixed and mobile telecommunications - by focusing on the evolution of the regulatory framework and by drawing some parallels with the evolution of the sector in the US. Given the major strategic importance of the sector, we highlight some of the challenges that lie ahead.
\end{abstract}

Keywords Fixed and mobile telecommunication networks $\cdot$ Telecommunications regulation · European Union · Institutional design

JEL Classification L43 $\cdot$ L5 $\cdot$ L96 $\cdot$ O52

Christos Genakos

c.genakos@jbs.cam.ac.uk

Martin Cave

martin.e.cave@btinternet.com

Tommaso Valletti

t.valletti@imperial.ac.uk

1 London School of Economics, London, UK

2 Cambridge Judge Business School, Cambridge, UK

3 AUEB, Athens, Greece

4 CEP, London, UK

5 CEPR, London, UK

6 European Commission, Brussels, Belgium

7 Imperial College London, London, UK

8 University of Rome Tor Vergata, Rome, Italy 


\section{Introduction}

Few sectors have undergone so rapid a transformation in the past 25 years as telecommunications. In 1993, the sector provided national and international voice services, leased lines, and little else. Mobile communications was still in its infancy, with penetration rates that could be counted on the fingers of one hand. Data traffic transmitted via the internet was emerging at that time from the rarefied US environments of the Defence Advanced Research Projects Agency (DARPA) and the National Science Foundation Network (NSFNET) and becoming both public and commercial-aided by the development of the World Wide Web. Social media were not to follow for nearly another decade.

In those 25 years, analogue transmission in the telecommunications sector has long given way to digital; but the sector's role as an enabler of the digital transformation of the economy and society is just beginning, with numerous predictions that almost every act of consumption and production — in both the private and the public sector, as well as of social intercourse-will be transformed by the new cluster of information and communication general purpose technologies. Hence, there is no doubt that telecommunications is a sector of major strategic importance.

By the second half of the twentieth century, in most of the world including Europe, telecommunications were characterized by both monopoly and public ownership: two characteristics that are often associated with certain benefits but also with a substantial dose of inertia and inefficiency. Thus, unlike information technology, telecommunications had to liberate itself from these latter tendencies through re-invention, while remaining under a form of indirect public control via regulation.

In this paper we summarize how this process has unfolded in Europe over the last 25 years and discuss how the regulatory regime has adapted, and, in particular, how it has in recent years shepherded the sector towards significant changes in market structure. Because terrestrial local access telecommunication networks are locationally specific, the opportunities for international trade and rivalry in telecommunications are limited: A network in Paris is no substitute for one in London; by contrast, electricity generated in France can be sold in the UK. At the same time, an operator that owns core or long-distance networks in adjacent countries can reduce costs by reconfiguring them in a less costly fashion that ignores national boundaries. The impact of the European single market has thus been felt chiefly through the free movement of capital and in the form of a uniform regulatory regime that applies in all Member States. It is the latter aspect which is considered here.

In Sect. 2 we note some regulatory landmarks in the process and mention some outcome changes. Section 3 describes how fixed telecommunications networks in Europe are emerging from a starting point of monopoly to a state that more closely approximates oligopoly. Section 4 evaluates Europe's success in achieving and maintaining effective competition in the mobile sector. Section 5 concludes. 


\section{The Long Road from Regulating Monopolists to Oligopoly}

For the most part of the twentieth century, European electronic communications were organized around state-owned posts, telephone, and telegraph (PTTP) service providers. The market for telecommunications services used to have a highly distorted price system, whereby international and long-distance call prices were significantly above cost, whereas local tariffs and rental charges were below cost. This system of cross-subsidization was typically regulated by the government: with the aim of promoting universal service. Although this shifted the financial burden to business customers, this system had adverse economic efficiency effects (Noam 1992; Thatcher 1999; de Streel 2008; Bauer 2013).

These arrangements began to be challenged in the 1970s due to a combination of technical, political, economic, and social developments. Important innovations and new technical capabilities changed telecommunications fundamentally and led to an understanding that information and communications technology (ICT) was one of the main drivers of economic growth. The US courts broke up AT\&T in 1982, and the auctioning of mobile licenses began in the early 1990s.

The need for large ICT investments in infrastructure and the realization that the telecommunications sector in Europe was lacking in dynamism led to a big push for change in the status quo. The European Commission (EC) became a promoter of sector reform in 1987 with the publication of the Green Paper on Telecommunications, which aimed at liberalizing all segments of the telecoms market, in a process that led in 1998 to the liberalization of voice telephony and infrastructure. Part of the transformation was also the establishment of independent National Regulatory Authorities (NRAs). Although no consensus could be found to establish a European regulatory agency, coordination among the NRAs is achieved through (initially the European Regulators Group and now) the Body of European Regulators of Electronic Communications (BEREC). In sum, the EU embarked in a little more than a decade on a major program to transform the telecoms sector.

The reforms that were implemented led to a virtuous cycle of increased competition, increased investment, price declines, and accelerated adoption. For example, Fig. 1 shows that in relation to a US benchmark, the EU was initially behind in access paths (fixed and mobile access lines per 100 inhabitants), but by 2000 the EU- $15^{1}$ had surpassed the US and by 2002 the EU- $28^{2}$ did so as well. A similar picture emerges in Fig. 2 if one looks at fixed broadband subscriptions, where the EU-15 has overtaken the US since 2007, with the EU-28 being very close by 2016.

After an interim regulatory regime that lasted 5 years (from 1998 to 2003), the European institutions (the Commission, the Council, and the Parliament) embarked upon a new regime, the framework of which has survived with relatively minor

\footnotetext{
1 The EU-15 comprises the following countries: Austria, Belgium, Denmark, Finland, France, Germany, Greece, Ireland, Italy, Luxembourg, Netherlands, Portugal, Spain, Sweden, United Kingdom.

2 The EU-28 includes, in addition to the EU-15, the following countries that joined after 2004: Bulgaria, Croatia, Cyprus, Czech Republic, Estonia, Hungary, Latvia, Lithuania, Malta, Poland, Romania, Slovakia, Slovenia.
} 


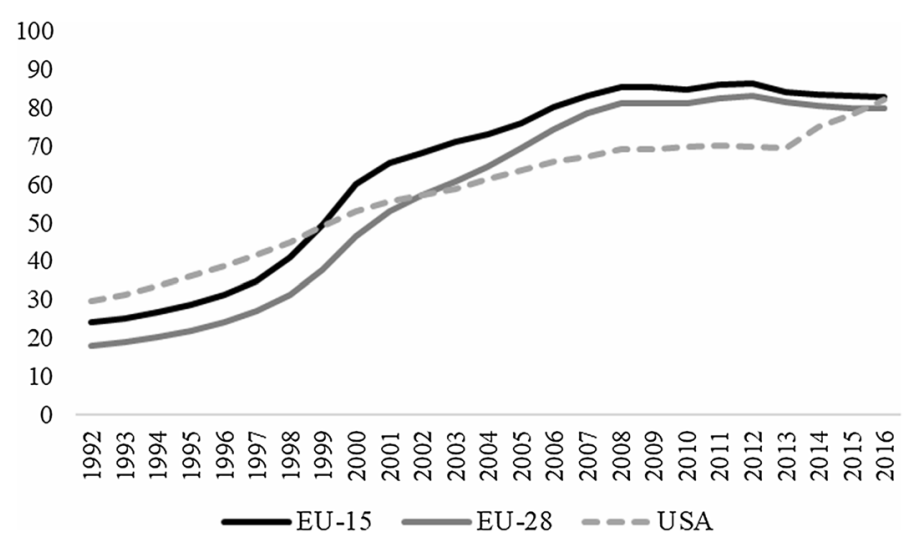

Fig. 1 Fixed and mobile telephone (subscriptions/100 people). Source: ITU World Communications Database

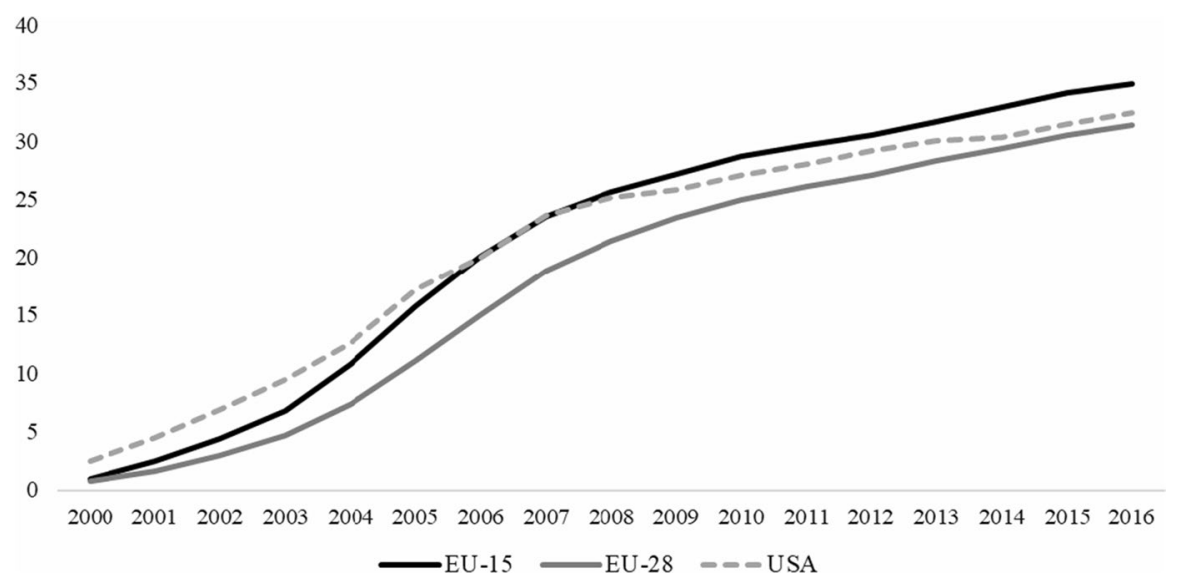

Fig. 2 Fixed broadband (subscriptions/100 people). Source: ITU World Communications Database

modifications for the following 15 years. ${ }^{3}$ Its longevity is due in large to the flexibility with which its deregulatory impulse is implemented. Sector-specific regulation of particular markets can be maintained only where firms are found in periodic market reviews to exercise significant market power (a forward-looking equivalent of the test of dominance that is used in European competition law). Since 2003 the number of markets that require such market reviews has fallen from 18 markets to foura set that excludes any retail market. By 2018, regulation was confined to a relatively small number of key wholesale markets, in which any operators with market power were usually obliged to provide access to interconnection with their networks

\footnotetext{
$\overline{{ }^{3} \text { Framework Directive 2002/21/EC and Access Directive 2002/19/EC. }}$.
} 


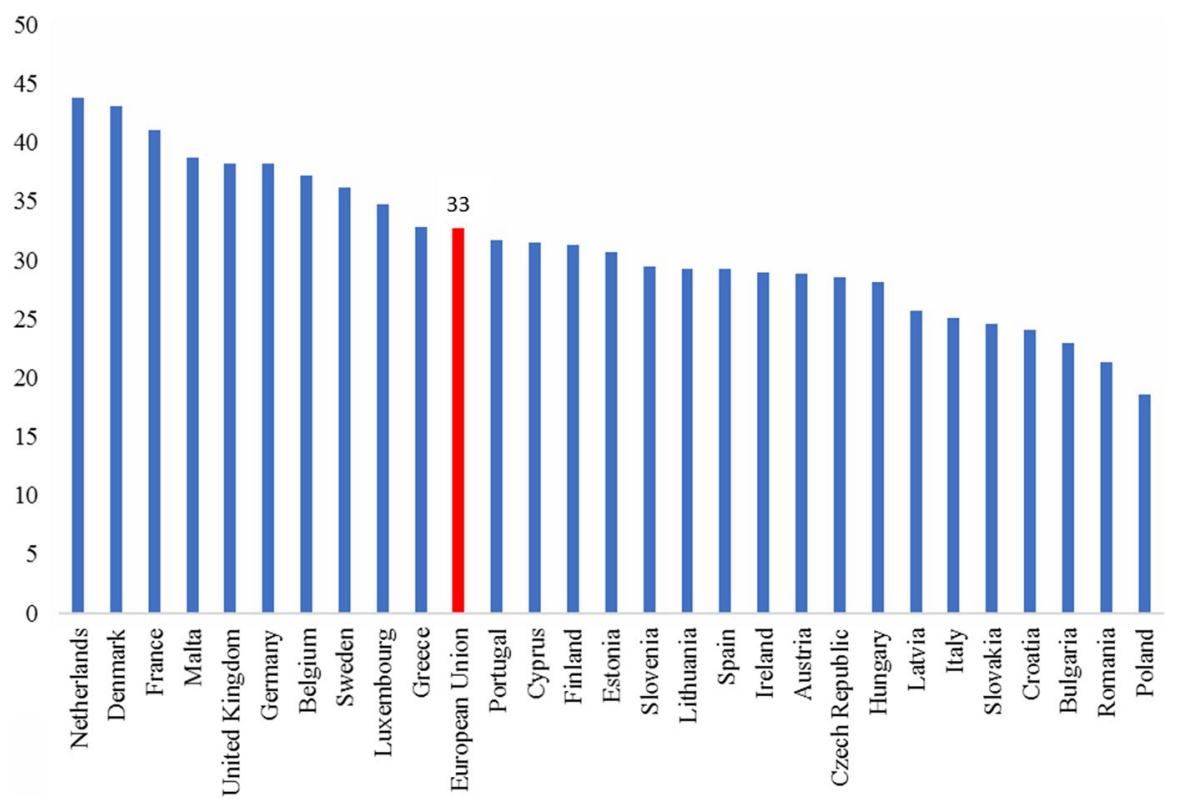

Fig. 3 Fixed broadband 2016 (subscriptions/100 people). Source: Broadband coverage in Europe, studies for the EC Open Data Portal

to competitors. The operation of the regime is a joint product of the EC and the 28 NRAs.

Yet, despite these successes, there are still two important challenges: The first is the harmonization and further integration of the European market. For example, the cross-country differences within the EU are very clear in Fig. 3, which depicts fixed broadband penetration in 2016. These disparities are an important challenge for the future of Europe. It is difficult to agree on a common European regulation when there is no such thing as an "average" European country.

Second, the regulatory approach so far was more successful in squeezing (static) efficiencies from the existing system than in stimulating the (dynamic) transition to the next generation of infrastructures and services, which require considerable investment in infrastructure. For example, although the US and EU have comparable penetration levels for fixed broadband subscriptions, there are clear differences when it comes to faster Next-Generation Access (NGA) networks (with speeds of 25 Mbps or higher). According to Yoo (2014), 82\% of US households were covered by NGA networks compared to only 54\% in Europe (based on 2011-2012 data).

The EU has sought to address the lack of network investment in a series of recent policy documents, which includes various Recommendations and Directives for next-generation networks (Cave and Shortall 2011; EC 2010). The regime as a whole has undergone reform, with a new European Electronic Communications Code (EECC) finalized in June 2018 (Council of the European Union 2018). Key areas of dispute were: how to maintain incentives for investment in powerful new fixed and mobile technologies; how to extend the coverage of such networks to 
poorer and more sparsely populated areas, so as to avoid a 'digital divide'; and how best to harmonize regulation further (Briglauer et al. 2017). But many of the fundamental features of the 2003 system are still in place.

\section{The Long ROAD in Fixed Telecommunications Networks: Creating Effective Competition}

The European fixed network sector, guided by the 2003 regulatory framework, has undergone major transitions in terms of technology and market structure. The framework has generally been pro-competitive and deregulatory and has combined stability with some flexibility. It has steered the sector from a position of substantial dominance by the various historical monopolists, to a patchwork of individual but still national market structures that can increasingly be characterized as oligopolies. This section outlines this process, with a focus on how the regulatory regime has promoted the development of infrastructure competition in each jurisdiction.

As noted, the regulatory framework has abandoned regulation of final retail markets as soon as suitable wholesale access markets can be developed. This has been accomplished by the promotion-in different degrees in the various member states-of a mixture of infrastructure- and access-based competition. More flexible access pricing rules which have allowed variation in charges across Member States have prevented the controversy and final abandonment of attempts at unbundling networks in the US in the decade after the passage of the US Telecommunications Act of 1996.

Initially the access-based variant relied on using the regulatory framework to mandate that the copper-based incumbent offer one or usually both of (mainly) two access products: a 'passive' product in the form of an unbundled copper loop, and a more comprehensive 'active' product (including electronic components) known as bitstream. The line taken by the European regulators that implemented this approach was generally to extend the degree of infrastructure competition by favoring unbundled loops, the access price of which was reduced. The degree of success of this is shown by the fact that, between 2003 and 2010, the ratio of unbundled loop to bitstream connections changed from 1-2.5 to 5-1 (Cave 2014). The success of this policy was reflected in the declining market share of incumbent operators among household broadband consumers, but with substantial variation across member states. Thus, the level of regulatory intervention has shifted upstream.

Over the same period, end-to-end infrastructure competition in the form of cable networks made some progress. Cable had historically been treated with benign neglect by European regulators - both at the national level and by the EC-which resisted including cable wholesale inputs in the same market with assets that were owned by telecommunications operators. The diverse legacy of analogue cable assets (varying from nearly $100 \%$ coverage in countries such as Belgium and the Netherlands to zero in Greece and Italy, with major countries such as France, Germany, Spain, and the UK somewhere in the middle) stood in the way of a uniform treatment. However, the success of the DOCSIS 3.0 digital standard encouraged cable investment and brought this form of competition more into the regulatory 
spotlight. ${ }^{4}$ The coverage of households by cable networks in the EU in 2016 reached $44.4 \%$ (but only $10.1 \%$ in rural areas).

A good deal of discussion has involved the relative impacts of access- and infrastructure-based fixed broadband on investment, prices, speeds, and take-up. An influential cross-country study by Grajek and Roller (2012) showed that access regulation increased investment by entrants but reduced that of incumbents and cut investment overall. Using microdata from the UK, Nardotto et al. (2015) show that unbundling the local loop did not increase the take-up of broadband services but delivered the benefit of improved quality. Competition from cable increased both take-up and quality. This study has not been replicated elsewhere.

The general conclusion of the studies that cover copper-based broadband is that full competition between infrastructures is the 'gold standard': It yields better results than access- based competition. However, it was unrealistic to expect an operator to invest in a copper network in the first decade of the 21 st century, with next-generation fiber networks on the horizon. In other words, the 'counterfactual' to accessbased competition was probably a (regulated) end-to-end monopoly-which was not an attractive prospect.

In recent years the issue of access-based competition has presented itself with particular acuteness in connection with the transition to fiber, where the historical monopolist, with an installed copper network, access to which was typically mandated, had to be coaxed to invest in fiber (Bourreau et al. 2012).

So European fixed networks adopted fiber late-particularly compared with Asia_and patchily: The lead was first taken by member states in Eastern Europe without ubiquitous copper networks, and thus not subject to the 'replacement effect': the consideration on the part of existing players that any fiber connection that they sold would entail the loss of a copper connection. By 2016, 23.7\% of EU households had access to a fiber-to-the-premises (FTTP) connection, and $48.2 \%$ to a VDSL/ fiber-to-the-node (FTTN) connection (EC 2017a).

What hung on the choice between these two fiber variants? FTTP was recognized as being more 'future-proof', but it was also a great deal more expensive, in circumstances where European households appeared to have a limited willingness to pay for the extra speed it offered. So, should the choice of variant be left to the investing company in accordance with the policy of technology neutrality, which is an element—but not a governing principle_-of the regulatory framework?

The European Commission spent some time between 2008 and 2010 dithering over this and other questions of how to regulate fiber, and this allowed member states to adopt divergent approaches. Some (notably Germany and the UK) imposed an obligation to supply active fiber-access products: equivalent to bitstream. This perpetuated and even enhanced the dependence of access seekers on the existing access provider. Others (notably, France, Portugal and Spain) promoted infrastructure competition by requiring that the incumbent make only ducts and poles

\footnotetext{
${ }^{4}$ DOCSIS (Data Over Cable Service Interface Specification) is a family of standards. The 3.0 variant, released in 2006, represented a major advance in data speeds.
} 
available to competitors: an access product that is significantly less extensive even than an unbundled copper loop (Shortall and Cave 2015).

Competition appeared to develop in different ways in the two groups. In the former, investments in local-access fiber were made largely by the incumbent. In the latter, a variety of alternative networks came forward to offer FTTP-including notably certain mobile operators-which were unencumbered by copper but had existing commercial relationships with customers.

These contrasting outcomes may have contributed to the significant change of approach in favor of 'competitive' FTTP that has been recently visible in the UK, where FTTN was originally favored. But it is difficult to combine the two approaches. The incumbent can seek to forestall FTTP investment by its rivals, by offering the threat to match the higher speeds that the rivals seek to offer either by a FTTP deployment or via intermediate technologies - such as G.fast-which offer speeds intermediate between FTTN and FTTP by taking the fiber closer to but not right up to the premises (Ofcom 2017).

Fiber has by now been installed for a long enough period to permit econometric estimation of the impact of regulation..$^{5}$ A number of studies show that more intrusive regulation of fiber assets deters fiber investment. In anticipation of this result, the EC had already relaxed the level of access regulation in relation to fiber: In 2013 the EC allowed access pricing rules that give greater flexibility to the access provider (EC 2013).

The developments described above form the basis of the claim that was made above that the past 15 years have seen a significant transition from monopoly to oligopoly in the EU: The new competitors are partly infrastructure and partly accessbased. How has regulation changed as a result?

A key aspect of the European regulatory framework as a whole is that it contains strong sunset provisions: For regulation to be continued in any market in any member state, a finding of significant market power (dominance in a prospective sense) has to be made in a periodic market review performed every 3-to-5 years. Since 2003, about three-quarters of the initial set of markets that were assumed to require regulation are no longer subject to the same obligatory analysis; this process is represented graphically in EC (2017b). In the course of this process, control of some wholesale markets has disappeared, and the regulatory control of retail priceswhere many firms operate in the various markets - has virtually ceased.

But a translation to oligopoly presents different challenges than a transition to competition, and a debate has been raging over whether the framework is robust enough to deal with the challenge of 'small numbers' markets. One form of potential abuse might be 'collective' dominance (also known as tacit collusion). Ultimately, the sector has considerable barriers to entry and only a handful of players repeatedly interacting with one another. But many regulators believe that showing this form of dominance under the regulatory framework has been rendered almost impossible by the demands that have been placed upon its demonstration by judgments of the European Court. Alternatively, there might be several firms that each exercise

${ }^{5}$ Briglauer et al. (2017, pp. 9-10) review the results. 
single-firm dominance: possibly by exploiting locked-in customers who are disengaged or are baffled by the difficulties that are placed in their way when they seek to 'search and switch' in bundled markets.

BEREC - the 'College' of European NRAs - has expressed the belief that additional instruments are required; it is not clear exactly what these would be. In any case, the EC appeared to believe that clarification or an extension of existing possibilities would suffice. Clarification took the form of publication by the Commission of a revised Guidance document on market analysis and significant market power, which sets out again the basis for a finding of collective and other forms of dominance (EC 2018). The drawback here is that the final decision on this matter will rest with a national or European Court—not with the Commission. An alternative approach is to go beyond asymmetric remedies-which can be applied only following a finding of dominance - to symmetric ones that apply to all operators. The new EECC (Council of the EU 2018) embodies a limited extension of this approach.

In summary, under the auspices of the European regulatory framework, the fixed network market place has changed in major respects since 2003-but with substantial national variation, as well as regional variation within member states. The direction of travel has been towards more competition of both the access- and the infrastructure-based kind.

Moreover, looking ahead, it is likely that impending changes in network design will change the nature of competition. In particular, changes that are associated with virtualization and software-defined networking - in the case of both fixed and mobile networks - have the capacity to allow a network to configure itself into separate slices. Each slice is capable of providing a different service, and each is capable of being decentrally controlled either by another physical network-to provide a specified uniform quality of service across the two interconnected networks-or to constitute a virtual network, which thereby dis-intermediates the physical network. For example, a service provider such as Netflix might lease a virtual network that is suited to the transmission of its own content. The end user would then choose the 'virtual Netflix network' to gain access to the relevant content.

A single physical network would then support multiple 'sitting tenants,' without enjoying a commercial relationship with the universe of end-users. While the 'true' physical network might remain a bottleneck for access to single-homing households, the nature of other commercial relationships would change.

The developments that are occurring and will occur have the capacity to redistribute market power in the value chain: both vertically and horizontally. This will impose further strain on the EU regulatory mechanisms-but they have already accommodated significant major changes.

\section{The Long Road in Mobile Networks: Maintaining Effective Competition}

The evolution of mobile technologies and the different policies/regulatory frameworks that have been followed by EU governments led to mobile telecoms markets' being developed in a completely different way from the fixed telecoms markets. 
Mobile telecommunication technologies were developed in successive generations, with the first one (1G) coming to operation for the first time in 1979 in the US. The first generation of mobile telecommunications was analogue and supported only voice. One of the most serious shortcomings of this technology was the lack of interoperability that did not allow cross-border roaming. Over time various digital standards were developed around the world. The US authorities chose to distance themselves from the process and let the market determine one (or several) specific standards (Gandal et al. 2003). ${ }^{6}$

On the contrary, in the EU, the regulators chose to impose a common standard (the so-called GSM), ${ }^{7}$ which was criticized at first. In retrospect, no one can doubt that this decision was inspired. The most important consequence of adopting this strategy in Europe is that the mobile industry has spread throughout the continent in a very short period of time, achieving higher penetration rates than in the US.

Whereas the first- and second-generation of mobile telecommunications systems were mainly designed for voice transmission, the next technological step was the development of systems for data transmission. Third-generation (3G) systems were designed to allow for increased capacity (higher transmission speeds) and richer content of the message.

In spite of the optimism that was shown at the beginning of the 21 st century, the stock market crisis of 2000-2001 - together with several technical problems-rendered the development of $3 \mathrm{G}$ difficult. Although most countries expected $3 \mathrm{G}$ to start operating in 2001-2002, the commercial launch of 3G typically took place at the beginning of 2004 or later.

Just as the substitution of analogue by digital technology enabled a larger number of operators, a similar phenomenon occurred with the transition between $2 \mathrm{G}$ and $3 \mathrm{G}$, which generated the possibility of awarding new licenses. Governments increased the number of licenses in an effort to introduce more competition into these markets (Gruber and Valletti 2003). Perhaps, the most controversial issue in Europe was the choice of mechanism for assigning the new $3 \mathrm{G}$ licenses (Klemperer 2002). Many countries chose auction systems, which were designed ad hoc; whereas others chose "beauty contests": imposing a number of criteria (geographic coverage, pricing, quality, etc.) and selecting the "best" firms (Fuentelsaz et al. 2008). This is in contrast with the US, where from 1993 onward the FCC has consistently used spectrum auctions to promote competition in different markets.

\footnotetext{
${ }^{6}$ The comparatively slow adoption of mobile phones in the US in the $90 \mathrm{~s}$ and early $2000 \mathrm{~s}$ has been attributed to a variety of reasons. Some argue that existing landline telephone network in the U.S. was generally quite good and low-price and new lines could be installed quickly and at low fees making it a good substitute, at least for some consumers that were not particularly interested in mobility. Others would argue that the main culprit was the payment model adopted in the US ("Receiving Party Pays") compared to EU ("Calling Party Pays").

${ }^{7}$ GSM is an open non-proprietary and interoperable digital standard for cellular mobile systems that operate in the 900 and $1800 \mathrm{MHz}$ band. The Groupe Speciale Mobile (GSM) - later renamed Global System for Mobile Telecommunications-was an initiative that combined private and public governance, with the aim to bring interoperability and cross-border roaming on a higher level (Pelkmans 2001; Dunnewijk and Hulten 2007).
} 
While 3G introduced data services-which expanded the functionality beyond voice and included multimedia, texting, and some limited internet access-it was not until 4G that a full Internet Protocol (IP)-based specification was available. The primary $4 \mathrm{G}$ protocol-LTE_-was designed to support mobile broadband and is the dominant industry standard today.

The next generation-5G-is expected to be introduced around 2020 and is not yet defined. The new technology generation is expected to push the frontiers of enhanced mobile broadband and the "Internet of Things" and will require significant investments from mobile operators. However, due to technological convergence and the resulting increased competition across markets, it is not clear that the required investment in the new technology will necessarily lead to an increase also in operators' revenues (Lemstra et al. 2017).

Mobile communications - in all EU-28 member states-are subject to regulation by an independent NRA. NRAs deal with a variety of tasks: licensing, numbering, broadcasting, monitoring universal service obligations, mandating access and interconnection, dispute resolution, application of competition law, market monitoring, and frequency allocation. The retail mobile market is essentially a national market (EC 2006). Consequently, there is no such thing as a European single market for mobile telecommunication. On the contrary, regulation is indeed fragmented, and every member state tries to make the best of it (Dunnewijk and Hulten 2007).

An example of this regulatory structure and its limits is the history of fixed-tomobile termination rates (MTRs). ${ }^{8}$ MTRs have been a hotly debated issue among regulators and academics worldwide. The level of these charges was perceived to be high in absolute terms, and also in relation to similar prices that are charged by fixed-network operators. Since the inception of the 2003 regime, every Member State has been obliged to conduct a market analysis of the mobile termination market; and - to the extent that market failures were found-remedies had to be introduced. Indeed, all the countries that completed the analysis did find problemswithout a single exception-and imposed (differential) cuts to termination rates.

However, both academics and mobile operators have argued that reducing the level of mobile termination rates can potentially affect the level of prices for mobile subscribers, causing a "waterbed" effect: Potential profits from termination could be passed on to mobile network subscribers, in the form of lower prices. If termination profits are capped, then retail prices could be adjusted too. Genakos and Valletti (2011), using data for the period 2002-2006, showed that, indeed, countries that introduced regulation that cut the termination rates experienced a significant waterbed effect: A ten percent reduction in mobile termination rates led to a $5 \%$ increase in mobile retail prices. In other words, cuts in termination rates before 2006 benefited those who were calling mobile phones but also led to the adverse consequence of increasing the yearly bill per mobile subscriber by roughly $€ 25$.

\footnotetext{
8 These are the charges mobile operators levy on other network operators for call termination. While, historically, MTRs on fixed networks have always been subject to regulation, mobile MTRs were instead initially unregulated and set by the receiving network.
} 
In more recent years, the telecommunications market has undergone a fundamental change: Mobile voice traffic has overtaken fixed-line call volumes, which has changed the economic forces that gave rise to the waterbed effect in the previous years. Capping termination rates would directly decrease the price of making mobile calls if those are mostly made to other mobile users. Genakos and Valletti (2015) empirically re-visit the earlier analysis, using an extended dataset that covered 27 countries until the end of 2011. These new results demonstrate that the ratio of mobile to fixed traffic is key. Countries that introduced termination rate regulation when mobile traffic was high did not experience any waterbed effect. On the contrary, countries that introduced the same regulation at a time of low mobile traffic experienced the waterbed effect overall: Retail prices first increased, as in Genakos and Valletti (2011); but then this effect considerably decreased over time due to the growing importance of mobile-to-mobile traffic. As a result of regulation, mobile termination rates are getting increasingly close to fixed termination rates, and thereby eliminating differences across operators and technologies-which makes sense in a phase of convergence.

A particular type of termination service is international roaming: the use of mobile phones on visited networks in foreign countries. A fundamental market failure originates from the transnational nature of roaming services that have been subject to EC regulation since 2007. A roaming voice call is either originated or terminated on a visited foreign network, to which the customer's home operator makes a payment for the wholesale service. Then the customer pays a retail price to his home network.

If a national regulator attempts to protect customers in its home country, it can do this only by affecting the retail prices that are charged by the home network; but if the corresponding wholesale prices, over which this regulator has no authority, remain high, low retail prices are not viable. Conversely, if a regulator intervenes to cut wholesale prices at home, the benefit goes entirely to foreign users.

For this reason, any feasible attempt to regulate roaming prices must involve the sectoral regulators of all countries involved, so that retail and wholesale prices can be controlled jointly. This is just what the EU meant to achieve with the "Roaming Regulation" of 2007. After several changes, all differential roaming charges in the EU were abolished in June 2017, when all EU mobile consumers could finally "roam like at home".

It is ironic that this policy is perceived as one of the greatest success of the EC, while no empirical assessment of it exists; nor is there a clear economic underpinning for the intervention, beyond the coordination problem that was mentioned above. In principle, there could be also here a waterbed effect at play-although the simultaneous introduction of cuts to roaming charges to all operators in the EU would make the identification of the causal impact on mobile prices much harder.

Finally, over recent years, Europe has experienced a wave of merger activity-especially in mobile telecommunications. As a result, competition authorities have focused a significant part of their enforcement activity on merger control. ${ }^{9}$

\footnotetext{
${ }^{9}$ In mobile telecoms, the EC recently cleared mergers in the Netherlands, Austria, Ireland, Germany and Italy; all were subject to divestiture requirements. The EC's concerns prevented a 4-to-3 merger in
} 
Competition and regulatory authorities typically focus on the pricing implications of mergers, as they are concerned that increased concentration could come with higher prices for end-users.

However, authorities seem to have paid less attention to the impact that such mergers could have on efficiencies and, especially, investments. Mobile operators argue that their revenues continue to decline due to increasing competition from global Internet players - such as Skype and WhatsApp-that offer alternative services. At the same time, operators argue that they are investing large sums into their broadband networks to meet the demand for data traffic. Consolidation, via mergers, is for them an attempt to maintain profitability levels and keep up with investments.

Key for competition authorities is to assess why mergers are needed to achieve higher levels of investment, as there could be other arrangements-such as network sharing agreements - that still allow reaching efficiencies on the supply side without creating increased market power on the pricing side.

This debate is particularly prominent in the European Union, as the completion of the Digital Single Market (DSM) is one of the top priorities for the EC. In 2015, the Commission published a strategy that outlined how it intends to achieve that goal; the EC stated that the completion of the DSM "could contribute $€ 415$ billion per year to [the EU] economy and create 3.8 million jobs".

A pillar of the strategy is addressing "fragmentation" in the telecoms sector, and the resulting smaller scale of operation. While fragmentation has been identified as one of the factors behind the worse financial results of European telecoms companies compared to their US, Japanese, and Korean counterparts, it has been interpreted differently by different stakeholders. For the Commission, fragmentation relates to fact that the availability, quality, and prices of services vary significantly across the continent, in telecoms markets defined by national borders. Mobile operators, instead, point to the fact that there are about 40 mobile network operators in the EU. Many operate in just one or two countries. By comparison, in the US there are four nationwide mobile operators (AT\&T, Verizon, Sprint, and T-Mobile). While the Commission as the EU's competition authority might be lenient in cross-border merger cases, the mobile operators appear more interested in achieving within-country consolidation.

Genakos et al. (2018) study the relationship between prices, investments, and market structure in the mobile telecommunications industry. Examining the experience of 33 countries in the period 2002-2014, they find that an increase in market concentrationboth organic and due to mergers - in the mobile industry generates a possible economic trade-off: While increased concentration would increase prices, investment per operator would also increase. ${ }^{10}$ For example, a hypothetical 4-to-3 symmetric merger would

\footnotetext{
Footnote 9 (continued)

Denmark in 2015 and a similar 4-to-3 merger in the UK was blocked in 2016. In 2018, new mergers have been cleared in Austria and the Netherlands.

${ }^{10}$ Genakos et al. (2018) obtain similar results also when using investment per subscriber instead of total investment. Note that given the near full saturation that these markets exhibit, investment per subscriber or per capita would yield very similar results.
} 
increase the bill of end-users by $16.3 \%$ on average. At the same time investment per operator would increase by $19.3 \%$, while total industry investment does not change significantly. Hence, the evidence on the impact of concentration on total industry investment is still not entirely conclusive, and more work is needed in this area.

An open question that the study of Genakos et al. (2018) raises-but cannot answer due to data limitations - is an assessment of the impact of investments on consumer surplus. Understanding where the extra investment money goes when a market gets more concentrated is an inescapable question for the proper assessment of the consequences of mergers in mobile telecommunications markets.

\section{Conclusions}

Within the period of a quarter of a century or so, the European telecommunications sector has been radically transformed from a group of state monopolies to a set of increasingly competitive national markets. This has been accomplished within the framework of a flexible regime of regulation, which combines significant deregulatory momentum with detailed implementation by national regulatory authorities. Liberalisation under independent regulation was an appropriate response to the technological and economic changes at the industry level, as well as the political conditions at the time. It facilitated the entry of new firms and increased competition. The rapid diffusion of new technologies and new services led to falling prices and much greater take up, which had wider beneficial effects on the European economy. It is fair to say that, overall, telecommunications markets represent one of the success stories of EU policy-making in network industries.

However, despite these successes over 25 years, the European telecommunications sector is not at the forefront of technology development or of technology adoption: It is behind the leading Asian countries and the US with regard to the latest and faster NextGeneration Access networks. Nor has the creation of a single European market made much progress.

These are the new challenges of the next 25 years. The chosen instruments for meeting these challenges are the Digital Agenda and the creation of the European Digital Market. An important regulatory component is now finalized: the EECC or European Electronic Communications Code (Council of the EU 2018). It remains to be seen how successful these policies will be.

Acknowledgements We thank Carlo Cambini, Tony Shortall, Mike Waterson, Larry White, two anonymous referees, and the participants of the special issue conference at Cambridge Judge Business School for many useful comments. Tommaso Valletti is currently serving as Chief Competition Economist at the European Commission. The opinions expressed in this paper are those of the authors alone and do not represent the views of any institution to which they are affiliated.

Open Access This article is distributed under the terms of the Creative Commons Attribution 4.0 International License (http://creativecommons.org/licenses/by/4.0/), which permits unrestricted use, distribution, and reproduction in any medium, provided you give appropriate credit to the original author(s) and the source, provide a link to the Creative Commons license, and indicate if changes were made. 


\section{References}

Bauer, J. (2013) The evolution of the European regulatory framework for electronic communications. IBEI Working Papers 2013/41 Telefonica Chair Series.

Bourreau, M., Cambini, C., \& Dogan, P. (2012). Access pricing, competition and incentives to migrate from 'old' to 'new' technology. International Journal of Industrial Organization, 30(6), $713-723$.

Briglauer, W., Cambini, C., Fetzer, T., \& Huschelrath, K. (2017). The European communications code: A critical appraisal with a focus on incentivizing investment in next generation broadband. Telecommunications Policy, 41(10), 948-961.

Cave, M. (2014). The ladder of investment in Europe: In retrospect and prospect. Telecommunications Policy, 38(8-9), 674-683.

Cave, M., \& Shortall, T. (2011). The extended gestation and birth of the European Commission's Recommendation on the regulation of fibre networks. Info, 13(5), 3-18.

Council of the European Union. (2018). Directive of the European Parliament and of the Council establishing the European Electronic Communications Code.

de Streel, A. (2008). Current and future European regulation of electronic communications: A critical assessment. Telecommunications Policy, 32(11), 722-734.

Dunnewijk, T., \& Hulten, S. (2007). A brief history of mobile communication in Europe. Telematics and Informatics, 24, 164-179.

EC. (2006). Annex to the communication from the commission to the council, the European parliament, the European economic an social committee and the committee of the regions, European electronic communications regulation and markets. COM(2006) 68.

EC. (2010). Commission recommendation of 20 September 2010 on regulated access to next generation access networks (NGA). COM(2010) 572.

EC. (2013). Commission recommendation of 11.9.2013 on consistent non-discrimination obligations and costing methodologies to promote competition and enhance the broadband investment environment. C(2013) 5761 final.

EC. (2017a). European commission broadband coverage in Europe. Available at: http://ec.europa.eu/ newsroom/document.cfm?doc_id=47092.

EC. (2017b). Market overview table, available at See 'market overview table". Available at: https:// ec.europa.eu/digital-single-market/en/news/definition-and-analysis-relevant-markets.

EC. (2018). Guidelines on market analysis and the assessment of significant market power under the EU regulatory framework for electronic communications networks and services (Text with EEA relevance) (2018/C 159/01).

Fuentelsaz, L., Maícas, J. P., \& Polo, Y. (2008). The evolution of mobile communication in Europe: The transition from the second to the third generation. Telecommunications Policy, 32(6), 436-449.

Gandal, N., Salant, D., \& Waverman, L. (2003). Standards in wireless telephone networks. Telecommunications Policy, 27(5-6), 325-332.

Genakos, C., \& Valletti, T. (2011). Testing the 'Waterbed' effect in mobile telephony. Journal of the European Economic Association, 9(6), 1114-1142.

Genakos, C., \& Valletti, T. (2015). Evaluating a decade of mobile termination rate regulation. Economic Journal, 125(586), 31-48.

Genakos, C., Verboven, F., \& Valletti, T. (2018). Evaluating market consolidation in mobile communications. Economic Policy, 33(93), 45-100.

Grajek, M., \& Roller, L.-H. (2012). regulation and investment in network industries: Evidence from European telecoms. Journal of Law and Economics, 55(1), 189-216.

Gruber, H., \& Valletti, T. (2003). Mobile telecommunications and regulatory frameworks. In G. Madden (Ed.), Emerging telecommunications networks, the international handbook of telecommunications economics (pp. 151-179). Chektenham: Edward Elgar.

Klemperer, P. (2002). How (Not) to run auctions: The European $3 \mathrm{G}$ telecom auctions. European Economic Review, 46(4/5), 829-845.

Lemstra, W., Cave, M., \& Bourreau, M. (2017) Towards the successful deployment of 5G in Europe: What are the necessary policy and regulatory conditions? CERRE project report.

Nardotto, M., Valletti, T., \& Verboven, F. (2015). Unbundling the incumbent: Evidence from the UK broadband. Journal of the European Economic Association, 13(2), 330-362. 
Noam, E. M. (1992). Telecommunications in Europe. New York: Oxford University Press.

Ofcom (2017) Encouraging investment in full-fibre networks and promoting competition. Available at: https://www.ofcom.org.uk/about-ofcom/latest/media/media-releases/2017/encouraging-investment -in-full-fibre-networks.

Pelkmans, J. (2001). The GSM standard: Explaining a success story. Journal of European Public Policy, $8(3), 432-453$.

Shortall, T., \& Cave, M. (2015). Is symmetric access regulation a policy choice? Evidence from the deployment of NGA in Europe. Communications and Strategies, 98, 17-42.

Thatcher, M. (1999). The politics of telecommunications. Oxford: Oxford University Press.

Yoo, C. (2014). US vs European broadband deployment: What do the data say? University of Penn, Institute for Law \& Economics Research Paper No. 14-35.

Publisher's Note Springer Nature remains neutral with regard to jurisdictional claims in publishedmaps and institutional affiliations. 